\title{
A contabilidade da gestão ambiental e sua dimensão para a transparência empresarial: estudo de caso de quatro empresas brasileiras com atuação global*
}

\author{
João Eduardo Prudêncio Tinoco** \\ LÉo TAdeu Robles***
}

S U MÁRIO: 1. Introdução; 2. Objetivos; 3. Desenvolvimento teórico; 4. Estudo de caso de empresas brasileiras; 5 . Considerações finais.

S UMMARY: 1. Introduction; 2. Objectives; 3 . Theory development; 4. Case study of Brazilian firms; 5. Final remarks.

Palavras-chave: contabilidade da gestão ambiental; transparência; sustentabilidade.

KEY WORDS: environmental management accounting; transparency; sustainability.

Este artigo, com base nos casos de quatro empresas brasileiras com atuação global, aborda a contabilidade da gestão ambiental, em estudo exploratório que permitiu identificar a preocupação com a sustentabilidade econômica e o desenvolvimento social, bem como a importância do tema para a pesquisa acadêmica e para o apoio às decisões gerenciais e seu papel efetivo na comunicação das ações empresariais, em um passo à frente dos ditames legais.

\footnotetext{
* Artigo recebido em dez. 2005 e aceito em ago. 2006.

** Doutor em ciências contábeis, FEA/USP; professor-assistente doutor do Programa de PósGraduação em Gestão de Negócios da Universidade Católica de Santos (UniSantos). Endereço: Rua Carvalho de Mendonça, 144 - Vila Mathias - CEP 11070-906, Santos, SP, Brasil. E-mail: tinocojoao@uol.com.br.

*** Doutor em administração, FEA/USP; professor-assistente doutor do Programa de Pós-Graduação em Gestão de Negócios da Universidade Católica de Santos (UniSantos). Endereço: Rua Carvalho de Mendonça, 144 - Vila Mathias - CEP 11070-906, Santos, SP, Brasil. E-mail: leotrobles@unisantos.br.
} 
Environmental management accounting and its dimension in business transparency: case study of four Brazilian firms with global activity

This article, based on four Brazilian firms with global action, addresses environmental management accounting. An exploratory study identifies the firms' concerns with economic sustainability and social development, as well as the subject's relevancy not only for further academic research, but also in supporting managerial decisions. The study shows effective role of environmental management accounting in communicating the firms' actions, a step ahead of legal constraints.

\section{Introdução}

A interferência do ser humano sobre os sistemas naturais, causando seu comprometimento, tem feito com que se discuta e se implemente cada vez mais ações que, ao contemplar a questão ambiental, visem não comprometer tanto a qualidade de vida da atual população e também a das próximas gerações.

A evolução das entidades ao longo do tempo evidenciou uma preocupação centrada na eficácia e eficiência dos sistemas produtivos. Mais recentemente, essa visão revelou-se insatisfatória, ficando evidente que o contexto de atuação das empresas a cada dia torna-se mais complexo e o processo decisório sofre restrições cada vez mais severas. Um dos componentes importantes dessa reviravolta nos modos de pensar e agir foi o crescimento da consciência ecológica, na sociedade, nos governos e nas próprias empresas.

Recentemente, a sociedade passou a demandar das empresas informações sobre a questão ambiental. Assim, a contabilidade, além do registro de transações econômicas, passa a apresentar eventos ambientais, assumindo o papel de divulgação das ações de gestão ambiental, tendo em vista prevenir e corrigir danos, bem como salvaguardar os patrimônios empresarial e nacional. Essa imposição independe da entidade ser ou não ambientalmente íntegra. Como explicitaram Lima e Viegas (2002:47),

a preocupação com a questão ambiental é ética e econômica. Dela depende a permanência da empresa no mercado. Nesse contexto, a contabilidade se atualiza ao buscar procedimentos que proporcionem a evidenciação da informação ecológica, promovendo a discussão do tema entre seus pesquisadores e profissionais.

A contabilidade da gestão ambiental, conforme Bergamin Jr. (1999), passou a ter status de ramo da ciência contábil a partir da publicação em fevereiro de 1998, do "Relatório financeiro e contábil sobre o passivo e custos am- 
bientais", pelo Grupo de Trabalho Intergovernamental de Especialistas para Padrões Internacionais de Contabilidade e de Relatórios das Nações Unidas (Isar - United Nations Intergovernamental Working Group of Experts on International Standards of Accounting and Reporting).

Bergamin Jr. (1999) diz que, paralelamente a esse trabalho, o Isar vem coordenando esforços com o Comitê Internacional de Práticas de Auditoria (International Auditing Practices Committee - Iapc), a fim de formalizar um conjunto de padrões de auditoria voltados para a verificação do desempenho ambiental relatado nas demonstrações contábeis.

A contabilidade, entendida como meio de fornecer informações para shareholders (acionistas) e para stakeholders (parceiros ou atores sociais relevantes), no enfrentamento desse desafio, deve também atender aos interessados na atuação com relação ao meio ambiente por parte das empresas, clarificadas em sistemas de gestão ambiental, explicitando suas respostas à sociedade no que tange à responsabilidade social e à questão ambiental, subsidiando o processo de tomada de decisão.

Por outro lado, a gestão da qualidade nas empresas passa pela obrigatoriedade de implantação de sistemas organizacionais e de produção que valorizem os bens naturais, as fontes de matérias-primas, as potencialidades do quadro humano criativo, as comunidades locais e pelo início de um novo ciclo onde a cultura do descartável e do desperdício seja coisa do passado. Assim, impõem-se às entidades atividades de reciclagem, incentivo à diminuição do consumo, controle de resíduos, capacitação permanente dos quadros profissionais, em diferentes níveis e escalas de conhecimento, fomento ao trabalho em equipe e às ações criativas.

A contabilidade da gestão ambiental alinha-se, portanto, aos esforços da sustentabilidade, não somente econômica, mas sobretudo humana.

Dessa forma, analisa-se a utilização da contabilidade da gestão ambiental como facilitadora do uso e compartilhamento de informações contábeis, para a otimização da eficiência do uso dos recursos naturais, a fim de reduzir o impacto e o risco ambiental e os gastos na preservação ambiental. A questão ambiental, pela sua relevância junto à sociedade moderna, tem de ser incorporada aos demonstrativos contábeis, pois seu impacto sobre os resultados empresariais ocorre a curto, médio e longo prazos.

Com base numa revisão bibliográfica sobre o tema, analisamos e comentamos os resultados econômicos, financeiros e ambientais de quatro empresas brasileiras, com inserção no mercado mundial, como exportadoras e importadoras de produtos e insumos; com grandes volumes transportados e manuseios de cargas nos portos brasileiros; conhecidas pela sua preocupação e atuação na questão ambiental, a partir de suas demonstrações contábeis e 
relatórios complementares publicados no Brasil e no exterior; complementada com entrevistas com profissionais dessas empresas e a análise de informações obtidas em seminários técnicos especializados.

\section{Objetivos}

Este artigo tem os seguintes objetivos:

v analisar a nova dimensão que se apresenta para a contabilidade ao incorporar informações sobre a questão ambiental, respondendo às exigências de uma sociedade mais consciente na utilização sustentável de recursos naturais;

v verificar o estado da contabilidade da gestão ambiental, a partir da análise de informações econômico-financeiras, estudando os casos de quatro empresas nacionais com atuação global;

v apontar, a partir das informações analisadas, os próximos passos para essa nova dimensão da contabilidade que, semelhantemente à questão ambiental para as estratégias empresariais, deve ser necessariamente incorporada aos demonstrativos contábeis, relatórios de administração, notas explicativas e pareceres dos auditores.

A relativa recentidade do tema abordado indicou a conveniência da adoção de uma metodologia tridimensional, ou seja, uma revisão bibliográfica do tema, tanto de estudos nacionais, quanto internacionais, análise dos demonstrativos econômicos, financeiros e socioambientais de quatro empresas brasileiras com inserção global, complementada com entrevistas junto a executivos dessas empresas e a participação em seminários técnicos especializados realizados pela Abamec-SP (2002) e pela Apimec-SP (2004), que têm como público-alvo profissionais do mercado de capitais e consultores e analistas de empresas e investimentos.

A pesquisa foi fundamentada no estudo de casos múltiplos, de quatro empresas nacionais: a Vale - Companhia Vale do Rio Doce; a Petrobras Petróleo Brasileiro S.A.; a CSN - Companhia Siderúrgica Nacional; e a CST - Companhia Siderúrgica de Tubarão. Foram analisados suas demonstrações contábeis, relatórios de administração, notas explicativas, pareceres dos auditores, bem como relatórios socioambientais, abordando questões relativas ao meio ambiente e seus reflexos na sustentabilidade econômica e social. 
De forma complementar, acessamos os instrumentos disponibilizados pelas empresas para atuação no mercado internacional de capitais, especificamente na Bolsa de Valores de Nova York. Em decorrência da negociação de papéis mobiliários nessa bolsa, as empresas devem fornecer informações pormenorizadas de seu desempenho econômico, financeiro, social e ambiental à Comissão de Valores Mobiliários Americana (Securities and Exchange Comission - SEC), utilizando um documento denominado formulário 20-F.

Esse fato, por si só, induziu a realização de entrevistas não-estruturadas e abertas com executivos das empresas estudadas, para se qualificar e aprofundar a questão básica da utilização ou incorporação aos demonstrativos contábeis das questões ambientais e determinar-se, com base nos casos, a utilização externa e aparente dessas informações e seu uso interno nas empresas em apoio às decisões empresariais.

Ou seja, a metodologia utilizada e as formas de levantamento das informações e de realização de entrevistas caracterizam o estudo como exploratório, pelo enquadramento do estudo na tipologia proposta por Yin (1990). A maior limitação do método do estudo de caso é a de não permitir generalização para a população, da qual extraímos uma amostra para pesquisa. Os estudos realizados para este artigo, embora com a profundidade adequada, têm como objetivo de uso a sua replicação, conforme dito anteriormente, e não sua generalização.

\section{Desenvolvimento teórico}

As inovações trazidas pela contabilidade da gestão ambiental estão associadas a pelo menos três temas:

v definição de custos, despesas operacionais e passivos ambientais;

、 forma de mensuração do passivo ambiental, com destaque para o decorrente de ativos de vida longa;

v utilização intensiva de notas explicativas e divulgação de relatórios ambientais abrangentes, bem como o uso de indicadores de desempenho ambientais - ecoindicadores - padronizados no processo de fornecimento de informações ao público.

Neste momento, em que as questões sociais, ambientais e de sustentabilidade estão sendo abordadas pela comunidade, Gray (2003) explicita que 
as questões críticas que afetam a humanidade estão, no geral, sendo ignoradas e há uma inadequação na forma como estão sendo tratadas.

O objetivo necessário de conservação do meio ambiente tende a levar a contabilidade a assumir controles dos seguintes aspectos:

V fornecimentos - de recursos mínimos e uso extensivo de materiais reciclados ou renováveis;

$\checkmark$ processos produtivos e investimentos em imobilizado - mínimo consumo de água e energia, mínima emissão atmosférica e mínima quantidade de resíduos;

v características do produto - mínimos vasilhames e embalagens, reciclagem e reutilização.

Esse novo fazer foi construído com ênfase a partir dos resultados da Rio-92, onde a noção de desenvolvimento sustentável se alastrou e se estruturou. A noção e os conceitos de sustentabilidade trazem como novo desafio os caminhos para a gestão ambiental.

\section{O novo paradigma - gestão ambiental}

Gestão ambiental é o sistema que inclui a estrutura organizacional, atividades de planejamento, responsabilidades, práticas, procedimentos, processos e recursos para desenvolver, implementar, atingir, analisar criticamente e manter a política ambiental. É o que a empresa faz para minimizar ou eliminar os efeitos negativos provocados no ambiente pelas suas atividades.

Logo, para que uma empresa passe realmente a trabalhar com gestão ambiental deve, inevitavelmente, mudar sua cultura organizacional e empresarial. A gestão ambiental tem se configurado como uma das mais importantes atividades relacionadas com qualquer empreendimento.

O gerenciamento ambiental passa a ser um fator estratégico para análise da alta administração das organizações, incluindo uma série de atividades a serem consideradas, como: formular estratégias de administração para o meio ambiente; assegurar a conformidade com as leis ambientais; implementar programas de prevenção à poluição; gerir instrumentos de correção de danos ao meio ambiente; adequar os produtos às especificações ecológicas; monitorar o programa ambiental da empresa de encontro ao conceito de excelência ambiental, como uma vantagem competitiva. 
O quadro 1 apresenta uma visão da gestão ambiental, explicitando aspectos da gestão de processos, gestão de resultados, gestão da sustentabilidade e gestão do plano ambiental.

$$
\text { Quadro } 1
$$

Visão geral da gestão ambiental

\begin{tabular}{|c|c|c|c|}
\hline $\begin{array}{l}\text { Gestão de } \\
\text { processos }\end{array}$ & $\begin{array}{l}\text { Gestão de } \\
\text { resultados }\end{array}$ & $\begin{array}{l}\text { Gestão de } \\
\text { sustentabilidade }\end{array}$ & $\begin{array}{l}\text { Gestão do plano } \\
\text { ambiental }\end{array}$ \\
\hline Exploração de recursos & Emissões gasosas & Qualidade do ar & $\begin{array}{l}\text { Princípios e } \\
\text { compromissos }\end{array}$ \\
\hline $\begin{array}{l}\text { Transformação de } \\
\text { recursos }\end{array}$ & Efluentes líquidos & Qualidade da água & Política ambiental \\
\hline $\begin{array}{l}\text { Acondicionamento } \\
\text { de recursos }\end{array}$ & Resíduos sólidos & Qualidade do solo & Conformidade legal \\
\hline $\begin{array}{l}\text { Transporte de } \\
\text { recursos }\end{array}$ & Particulados & $\begin{array}{l}\text { Abundância e } \\
\text { diversidade da flora }\end{array}$ & Objetivos e metas \\
\hline $\begin{array}{l}\text { Aplicação e uso } \\
\text { de recursos }\end{array}$ & Odores & $\begin{array}{l}\text { Abundância e } \\
\text { diversidade da fauna }\end{array}$ & Programa ambiental \\
\hline $\begin{array}{l}\text { Quadros de riscos } \\
\text { ambientais }\end{array}$ & Ruídos e vibrações & $\begin{array}{l}\text { Qualidade de vida } \\
\text { do ser humano }\end{array}$ & Projetos ambientais \\
\hline Situações de emergência & Iluminação & Imagem institucional & $\begin{array}{l}\text { Ações corretivas e } \\
\text { preventivas }\end{array}$ \\
\hline
\end{tabular}

A primeira dúvida que surge ao considerarmos a questão ambiental do ponto de vista empresarial é o aspecto econômico. Qualquer providência que venha a ser tomada em relação à variável ambiental, surge a idéia de que as despesas aumentam e o conseqüente acréscimo dos custos do processo produtivo.

Donaire (1999:51) menciona que

algumas empresas, porém, têm demonstrado que é possível ganhar dinheiro e proteger o meio ambiente mesmo não sendo uma organização que atua no chamado "mercado verde", desde que as empresas possuam certa dose de criatividade e condições internas que possam transformar as restrições e ameaças ambientais em oportunidades de negócios. 
Existem três razões básicas para uma empresa adotar essa especificidade da contabilidade:

、 gestão interna - está relacionada com uma ativa gestão ambiental e seu controle, visando reduzir custos e despesas operacionais e melhorar a qualidade dos produtos;

v exigências legais - a crescente exigência legal e normativa pode obrigar os administradores a controlarem mais seus riscos ambientais, sob pena de multas e indenizações;

v demanda dos parceiros sociais - a empresa está submetida cada vez mais a pressões internas e externas. Essas demandas podem ser dos clientes, empregados, organizações ecológicas, seguradoras, comunidade local, acionistas, administração pública, bancos, investidores etc.

O quadro 2 mostra a classificação dos tipos de contabilidade da gestão ambiental proposta pela EPA (2002).

\begin{tabular}{|lll|}
\hline \multicolumn{3}{c|}{ Quadro 2 } \\
& Tipos de contabilidade da gestão ambiental \\
\hline Discriminação & Enfoque & Dirigido ao usuário \\
\hline Contabilidade nacional & Macroeconômico, economia nacional & Externo \\
Contabilidade financeira & A empresa & Externo \\
Contabilidade gerencial & A empresa, departamentos, & Interno \\
ou de custos & linha de produção etc. & \\
\hline Fonte: $<$ http://es.inel.gov/partners/acctg/acctg.htm>. & \\
\hline
\end{tabular}

Tendo em vista a tipologia proposta no quadro 2, este artigo está focado basicamente na contabilidade gerencial ambiental. Podemos definir então a contabilidade da gestão ambiental (CGA), de acordo com a Divisão para o Desenvolvimento Sustentável das Nações Unidas, como "uma abordagem combinada que facilita a transição de informação da contabilidade financeira e da contabilidade de custos para aumentar a eficiência de materiais, reduzir o impacto e o risco e reduzir os custos de salvaguarda ambiental". 
A utilização da contabilidade de gestão ambiental pode proporcionar grandes reduções de custos na gestão de resíduos, dado que os custos de manuseio e de deposição de resíduos são relativamente fáceis de definir e de imputar a produtos específicos. Outros custos/despesas ambientais, incluindo os da conformidade ambiental, legais, deterioração da imagem da empresa, riscos e responsabilidade ambiental, são mais difíceis de avaliar. A contabilidade de gestão ambiental, segundo a EPA (2002):

v está focalizada nos custos internos à companhia;

$\checkmark$ não inclui custos externos à sociedade;

v dá ênfase particular na contabilidade para custos ambientais;

$\checkmark$ a sua informação pode ser usada para a maioria de tipos de atividade ou de tomada de decisão da gerência dentro de uma organização, mas é particularmente útil para atividades ambientais proativas da gerência.

Os problemas ambientais que afetam as empresas poderão ser reduzidos, ou até eliminados, se forem adotadas metodologias inovadoras de gestão no trato ambiental. Esses problemas tornam as empresas menos competitivas, já que incrementam seus custos, tornando-as débeis perante os concorrentes, podendo, inclusive, levar ao encerramento das atividades operacionais.

Ademais, a poluição e os impactos ambientais de toda ordem prejudicam a comunidade, gerando problemas de saúde para os cidadãos e gastos crescentes para o poder público. Entre essas metodologias, que as empresas podem lançar mão para adequar-se à competitividade e à sustentabilidade econômica, podemos destacar o uso do balanço de massa.

Um balanço de massa poderá ser elaborado para um conjunto específico de insumos ou processos, ou para todos os insumos e resíduos de uma empresa. O objeto central do balanço aos processos é o registro dos insumos utilizados na empresa.

O balanço de massa é uma equação que se baseia no princípio de que "tudo o que entra terá de sair ou ficar estocado", dessa forma propõe-se o registro e o acompanhamento dos fluxos de materiais, segundo uma análise de entrada e saída no processo produtivo. Conforme a Divisão para o Desenvolvimento Sustentável das Nações Unidas (2001:36):

com o aumento dos custos em gestão de resíduos e em cumprimento da legislação ambiental, além da necessidade de melhorar a eficiência dos materiais utilizados em mercados competitivos, o registro dos fluxos de 
materiais em toda a empresa tem sido a ferramenta mais importante na procura de melhorias, quer na prevenção de resíduos, quer na utilização de uma produção mais limpa.

Segundo Tinoco e Kraemer (2004), todos os itens, componentes do processo produtivo, que incluem normalmente matérias-primas, materiais auxiliares, embalagens, água e energia, são mensurados em unidades físicas de massa $(\mathrm{kg}, \mathrm{t})$, de volume $\left(1, \mathrm{~m}^{3}\right)$ ou energia (MJ, $\mathrm{kWh}$ ). O consumo dos diversos insumos no processo produtivo, em nível de centros de custos e de produtos, é comparado com as quantidades produzidas e vendidas, bem como os resíduos e as emissões. $\mathrm{O}$ balanço de massa objetiva a melhoria da eficiência na gestão dos insumos em termos econômicos, sociais e ambientais, ou seja, de ecoeficiência.

Os balanços de massas podem ser elaborados para indicar as quantidades de matéria-prima e outros materiais secundários consumidos no processo produtivo, efetivamente incorporados ao(s) produto(s) final(is) e a quantidade que é desperdiçada, como resíduos e emissões líquidas ou gasosas. O desenvolvimento dos balanços de massa é geralmente elaborado em quilogramas e acompanhado por balanços de energia em kWh e balanços de água em $\mathrm{m}^{3}$.

Para agregar e avaliar a informação para uma análise desse tipo, o sistema de informação da empresa terá que estar capacitado para fornecer informações sobre as quantidades compradas e consumidas, produzidas e desperdiçadas. Visando melhorar a qualidade de informação ambiental disponível, bem como sua consistência, pode-se definir um sistema regular de acompanhamento.

O sistema de informação do balanço de massa permite obter e divulgar, periodicamente: dia/semana/mês/ano, informações financeiras, físicas e qualitativas sobre a origem das entradas de matérias-primas, materiais auxiliares, insumos em geral, produção e saídas de produtos, emissões e resíduos. Esse sistema deve estar vinculado à contabilidade financeira e à contabilidade de custos/gerencial.

\section{Estudo de caso de empresas brasileiras}

Em 27 de junho de 2002, aconteceu o Seminário da Abamec-SP com o tema "Meio ambiente e os resultados financeiros" e, em 11 de março de 2004, a Apimec-SP realizou o seminário "O meio ambiente e os resultados financeiros nos setores petróleo, gás e mineração”. Nesses seminários, várias empresas industri- 
ais apresentaram os resultados econômicos, financeiros, sociais e ambientais de sua política de gestão ambiental. Entre elas, optamos por analisar os casos da Companhia Siderúrgica Nacional - CSN; da Petróleo Brasileiro S.A. — Petrobras; da Companhia Vale do Rio Doce; e da CST — Companhia Siderúrgica de Tubarão.

A escolha pode ser justificada pela possibilidade de se contar com demonstrações financeiras publicadas nos EUA, para três dessas empresas, em função de exigências legais locais e pela possibilidade aberta aos pesquisadores de terem contato com executivos dessas empresas, complementando dados para o estudo do caso. A CST, embora não opere no mercado acionário internacional, tem-se notabilizado por uma expressiva e consistente atuação ambiental responsável, conforme veremos adiante.

\section{Companhia Siderúrgica Nacional (CSN)}

A CSN evidenciou, em 2002, que tem sua política ambiental justificada também pela exigência de mercados externos, onde as certificações são uma prática, inclusive as do tipo selos "verdes", e mesmo em função do mercado nacional; no qual, conforme pesquisa do Instituto Ethos 2001, citada pela empresa, $22 \%$ dos consumidores brasileiros privilegiam ou punem concorrentes pelo desempenho ambiental. Outra questão levantada é a submissão à auditoria ambiental como exigência de clientes, para determinar o desempenho do processo e a higiene do produto.

A política ambiental se materializa pela adoção dos princípios de:

v ecoeficácia - melhoria contínua em consumos e redução de perdas específicas por volume produzido, tratamento da poluição como forma de redução de custos marginais, diminuição de custos da reposição de perdas e dos de tratamento;

、 alavancagem - acesso a financiamentos para crescimento do negócio, vinculados à demonstração do desempenho ambiental, sujeição à auditoria ambiental dos organismos de financiamentos;

v saúde ocupacional - diminuição de exposição ocupacional, redução de acidentes, absenteísmo e de riscos de liabilities, melhoria do clima organizacional e moral (orgulho de pertencer);

v valor de mercado - redução de passivos ambientais, valorização em bolsas pelo tripé bottom line, menor risco do capital investido e a responsabilidade social e ambiental como fator de solidez e representação de capacidade de investimento; 
v imagem corporativa - defesa do valor da "marca";

v hedge ambiental - redução de riscos futuros de descontinuidade operacional, prevenção de passivos futuros advindos de eventuais multas, indenizações e compensações, de custos tangíveis/intangíveis de recuperação de imagem/marca e eliminação de custos crescentes com seguro.

Para a CSN, a concepção de econegócios tem ampliado seu mercado. Um exemplo é a evolução da sua taxa de reciclagem, inclusive com a implementação do programa Reciclaço, em iniciativa conjunta com a Metalic, destinado a recuperar latas de aço para bebidas pós-consumo, abrangendo o credenciamento de sucateiros; a realização de eventos; e a implantação de postos próprios de coleta em barracas de praia, bares, hotéis, restaurantes etc.

A CSN evidenciou que, em função de produção mais limpa, vem ampliando sua receita pelo processamento de resíduos transformados em produtos vendidos para a aplicação em outros processos industriais, representando uma taxa de crescimento de cerca de $30 \%$ ao ano, no período de 1998 a 2001, alcançando um faturamento de $\mathrm{R} \$ 82,5$ milhões.

Além disso, no mercado de econegócios, a CSN tem alcançado redução de custos nas diversas áreas da empresa, como: sinterização por meio de material particulado retido em precipitadores, que retorna como matéria-prima, provocando uma economia de $\mathrm{R} \$ 700 \mathrm{mil} / \mathrm{ano}$; alto-forno que, com o uso de gases provenientes do sistema de controle de poluição como fonte energética, gera uma economia de $\mathrm{R} \$ 96$ milhões/ano; e o material particulado dos sistemas de controle (400.000 t/ano), que retorna como matéria-prima, com economia de R\$ 3,5 milhões/ano. Outras áreas da CSN, como aciaria e coqueria também têm apresentado resultados favoráveis.

\section{Petróleo Brasileiro S.A. (Petrobras)}

Em 2004, a Petrobras apresentou sua política ambiental, evidenciando sua missão e visão do futuro, compromissos estratégicos, evolução do negócio, agenda positiva de atuação, riscos inerentes ao negócio, programa Pegaso, vazamentos, taxa de freqüência de acidentados com afastamento, investimentos e custos em meio ambiente, prêmios de seguros e multas ambientais aplicadas.

Expôs que a sua agenda positiva de atuação visa viabilizar novas fontes de energia ambientalmente mais saudáveis. $O$ expositor realçou que a empresa vem mantendo seus esforços na preservação do meio ambiente através do "Programa de Excelência em Gestão Ambiental e Segurança Operacional" (Pegaso), tendo 
sido gastos, em 2003, $\mathrm{R} \$ 2,3$ bilhões, com previsão para todo o programa de $\mathrm{R} \$ 6,8$ bilhões. O sucesso desse programa pode ser medido pela queda significativa no nível de vazamento de óleo e derivados ocorrido durante o programa (iniciou-se em 2000, com término então previsto para o final de 2003), saindo de um vazamento máximo ocorrido em 2000 de $5.983 \mathrm{~m}^{3}$ para $276 \mathrm{~m}^{3} \mathrm{em} \mathrm{2003.} \mathrm{O}$ número das fatalidades também apresentou uma queda de 10\% (empregados próprios e contratados). Comentou, ainda, que 100\% das unidades operacionais no país possuem certificação ISO 14001 e BS 8800 ou OHSAS 18001.

Apresentou, ainda, como vantagens do programa de gestão ambiental, a redução do consumo de energia, que passou de 142.545 tEP (tonelada equivalente de petróleo), em 1999, para 91.834 tEP em 2003, com reflexos positivos econômicos e financeiros. Os prêmios de seguro por conta do programa de gestão ambiental após terem um acréscimo acentuado no período 2000 a 2002 reduziram-se substancialmente em 2003, passando de $\mathrm{R} \$ 136,47$ milhões em 2002, para R\$90,42 milhões em 2003.

\section{Companhia Vale do Rio Doce (Vale)}

Em 2004, a Companhia Vale do Rio Doce apresentou sua política de gestão ambiental. Explicitou que o objetivo principal da gestão ambiental da Vale é o de salvaguardar valor para os acionistas, ou seja, permitir o desenvolvimento sustentável para os acionistas, dizendo que esse conceito pressupõe "garantir que os acionistas do futuro terão resultados iguais ou melhores que os acionistas do presente". Evidenciou o expositor da Vale que as partes interessadas no relacionamento da empresa no que tange ao meio ambiente são: clientes; fornecedores; comunidades (local, regional e global); órgãos políticos e ONGs; investidores, financiadores e seguradoras; leis, normas e regulamentos; concorrentes; e empregados e sindicatos.

Expôs também que a legislação ambiental é complexa, abrangente, e está em permanente mudança. Evidenciou que os principais objetivos do Sistema de Gestão e Qualidade Ambiental — SGQA da Vale são: inserir a variável ambiental na gestão da empresa, visando salvaguardar e agregar valor; identificar o controle dos aspectos, impactos e riscos ambientais; estabelecer e atender a política e os objetivos e metas ambientais, incluindo a conformidade legal; perceber oportunidades para aprimoramentos operacionais e ambientais - custo/resultado; e monitorar e aperfeiçoar o desempenho ambiental — evitar surpresas. 
O expositor da Vale fez uma palestra de caráter qualitativo, não apresentando nenhuma cifra, com referência a custos, despesas, passivos ou ativos ambientais.

\section{Companhia Siderúrgica de Tubarão (CST)}

Em exposição realizada em 2002, no seminário da Abamec-SP, a CST divulgou que tem entre suas prioridades empresariais o desenvolvimento sustentável da sociedade e o respeito ao meio ambiente. Assim, considera prioridade em sua política empresarial a existência de um sistema de gestão ambiental, que considera o desenvolvimento tecnológico e o atendimento às expectativas das partes interessadas, gerando, continuamente, melhorias que diminuam os eventuais impactos adversos e resultem em benefícios para a sociedade.

Nesse sentido, todo o corpo diretivo, gerencial e de colaboradores assumem como compromisso: estabelecer objetivos e metas ambientais associados aos aspectos ambientais levando em consideração opções tecnológicas e requisitos financeiros.

Em outubro de 1996, foi criada uma gerência especializada para a manutenção dos sistemas e equipamentos de controle ambiental atmosférico. Com o funcionamento e adequada manutenção dos EPAs - equipamentos de proteção ambiental, a empresa começou a ter ganhos econômico-financeiros. Os pósrecuperados são vendidos e/ou recirculados no processo industrial da CST, propiciando que a receita gerada por área seja de $75 \%$ do orçamento da gerência.

Na gestão de resíduos sólidos, até o ano de 2001, a CST já produziu coprodutos em volumes significativos. O resultado também foi de aprimoramento tecnológico, capacitação, interação com clientes e parceria com universidades e centros de pesquisa.

No aproveitamento dos gases e calor, em seu modelo energético baseado no aproveitamento dos gases gerados em seu processo, e do calor do apagamento do coque, a CST possui uma potência geradora de energia elétrica da ordem de $225 \mathrm{MW}$, quantidade superior à sua própria demanda. A energia elétrica gerada na central termelétrica, além de evitar a compra de energia de terceiros, a um custo da ordem de $\mathrm{R} \$ 15$ milhões mensais, propicia uma receita adicional de $\mathrm{R} \$ 670$ mil mensais, com a venda da energia excedente.

A empresa ainda apresenta outros ganhos, de acordo com o seu expositor:

v fortalecimento do relacionamento com a comunidade regional pela doação de escória de aciaria, útil na pavimentação de ruas e estradas vicinais; 
v desde 1995, a CST não recebe qualquer notificação de descumprimento da legislação ambiental;

v a empresa foi a primeira que o Unibanco lançou um Company profile sobre SRI - socialy responsible investing.

\section{Demonstrações contábeis publicadas}

As empresas Petrobras, CSN e Vale divulgam seu desempenho econômico e financeiro (subsidiariamente social e ambiental) no Brasil e nos EUA, enquanto a CST divulga no Brasil.

A Petrobras divulgou para seus stakeholders suas demonstrações financeiras relativas ao exercício de 2003, no jornal Gazeta Mercantil, do dia 12 de março de 2004. O relatório anual contempla 29 páginas, começando na página A-21 até a página A-50. Esse relatório inclui uma mensagem aos acionistas (feita pelo presidente), relatório da administração, demonstrações contábeis, notas explicativas, pareceres dos auditores e do conselho fiscal. Evidencia, em várias passagens do relatório, informações qualitativas e financeiras no que tange às questões ambientais, detalhando-as. Essas são, de certa forma, assemelhadas às reveladas no seminário promovido pela Apimec-SP.

Todavia, verificou-se que essas informações não foram auditadas, o que empobrece o relatório anual, podendo sujeitar-se a vieses. A nota explicativa 22 , que trata do meio ambiente, diz textualmente que não foi auditada, conforme página A-49 do jornal Gazeta Mercantil.

A Vale divulga suas informações econômicas, financeiras, ambientais e sociais em jornais econômicos de grande circulação, bem como junto à CVM - Comissão de Valores Mobiliários e na Security Exchange Commission - SEC. As informações relativas ao exercício de 2002 foram arquivadas em ambas as autarquias em 24 de março de 2004. O relatório da Vale, à semelhança das outras empresas, é bastante detalhado e profundo, evidenciando informações qualitativas e financeiras. No relatório apresentado à CVM, explicita na página 42, no item 10.15 - Custos Ambientais e de Recuperação e Restauração - , que "os gastos relacionados ao atendimento de regulamentos ambientais são debitados ao custo de produção ou capitalizados quando incorridos". A Vale gerencia suas relações com o meio ambiente como um fator estratégico, tendo como premissa o pleno atendimento da legislação aplicável, e as diretrizes e normas internas estabelecidas por seu sistema de gestão ambiental, em pleno acordo com as especificações da Norma ISO 14001. A Vale desenvolve programas contínuos que têm por ob- 
jetivo minimizar o impacto ambiental de suas operações de mineração, bem como reduzir os custos que venham a incorrer com o término das atividades da cada lavra. Em 2003, a provisão para passivos ambientais corresponde ao montante de R $\$ 232$ milhões (R \$ 52 milhões em 2002) classificada em "outros" no exigível a longo prazo.

A CST divulga seu desempenho econômico, financeiro, social e ambiental no Brasil, em jornais econômicos de grande circulação e em seu site: $<$ www.cst.com.br $>$.

O relatório anual, relativo ao exercício de 2004, apresenta referências no relatório da administração e nas demonstrações financeiras de informações pertinentes à contabilidade e à gestão ambiental. Esses demonstrativos continham informações sobre investimentos em equipamentos e sistemas de controle ambiental e financiamentos externos obtidos junto ao European Investment Bank (EIB). A empresa evidencia em notas explicativas, como a nota 20 - custo ambiental - , que "os gastos relacionados ao atendimento de regulamentos ambientais são debitados ao custo de produção ou capitalizados quando incorridos". Nessa mesma nota verifica-se que:

a Companhia gerencia suas relações com o meio ambiente de acordo com as especificações da Norma ISO 14001 e desenvolve programas contínuos que têm por objetivo minimizar o impacto ambiental, de suas operações conforme atesta a certidão negativa de débito ambiental (CNDA no 386/03 expedida no final de 2003. Além disso, a CST é auditada em todos os aspectos econômicos, financeiros, sociais e ambientais, conforme relatório dos auditores Pricewaterhouse\&Coopers.

A carta-relatório dos auditores expressa em seu primeiro parágrafo:

procedemos à revisão dos indicadores de desempenho ambiental e social apresentados nas páginas 3 (Indicadores Ambientais) e 24 (Balanço Social) do Relatório da Administração da Companhia Siderúrgica de Tubarão - CST, referente ao exercício social findo em 31 de dezembro de 2004. A apuração, a compilação e o cálculo dos indicadores de desempenho mencionados são de inteira responsabilidade da CST. O propósito de nossos trabalhos foi confirmar que os indicadores de desempenho ambiental e social contidos no Relatório da Administração da CST, referentes ao exercício social de 2004, estão suportados pelos sistemas de informações gerenciais e contábeis, pelos instrumentos de monitoramento ambiental da Companhia, pela estrutura de controles internos, e estão reportados de forma apropriada em todos os seus aspectos relevantes. 
Por causa da inserção no mercado internacional, tanto a Vale, quanto a Petrobras e a CSN divulgam informações de seu desempenho econômico, financeiro, social e ambiental à Comissão de Valores Mobiliários Americana SEC. Utilizam para isso um documento denominado formulário 20F. Esse documento, que se divide em três partes, inclui desde informações-chave da empresa, relativas a dados financeiros selecionados e fatores de risco, análise e perspectivas operacionais e financeiras, informações financeiras, contendo, demonstrações consolidadas e demais informações financeiras, e, ainda, processos judiciais e administrativos, divulgações quantitativas sobre risco de mercado, balanços dos últimos cinco anos, demonstrativos dos fluxos de caixa, notas explicativas dos demonstrativos financeiros, bem como dos pareceres dos auditores independentes, além de outras informações relevantes.

Foi verificado, pelo formulário $20 \mathrm{~F}$, que as empresas revelaram vários acidentes ambientais em que se envolveram, nos últimos anos, detalhando-os, inclusive arrolando os processos judiciais a que estão sujeitas, especificando multas que estão recorrendo, além de notas relativas a passivos ambientais que são evidenciadas, o que não ocorre, com o mesmo detalhamento, no Brasil. Vale ressaltar, que nas demonstrações contábeis publicadas pelas empresas no Brasil a partir de 2002, houve um maior detalhamento dos eventos e riscos ambientais, mas sem o mesmo rigor do que é divulgado externamente.

Uma análise dos relatórios da CSN, no site <www.csn.com.br > ; da Vale, em <www.vale.com.br>; e da Petrobras em <www.petrobras.com.br>, extraída do Formulário 20F revela-nos que o nível, a abrangência e o rigor da informação são muito mais extensos e profundos quando divulgados junto à SEC americana. Além disso, os relatórios socioambientais publicados no exterior são auditados, o que não ocorre no Brasil, independentemente dessa informação ser divulgada no corpo das demonstrações contábeis, no relatório da administração, na carta do presidente, ou em relatórios ambientais ou socioambientais, como as empresas os vêm designando ultimamente.

Todavia, merece destaque a CST, que em seu relatório anual de 2004, evidenciou que todas as operações econômicas, financeiras, sociais e ambientais foram objeto de auditoria, destacando-a no contexto das empresas brasileiras, já que são raras as empresas que são auditadas em seus aspectos sociais e ambientais.

Os casos analisados permitem afirmar que, mesmo em organizações de ponta e que apresentam políticas e estratégias claras com relação à gestão ambiental, sua contabilidade se apresenta mais em função da obediência a preceitos legais, embora existam internamente programas ambientais que têm seu desenvolvimento e acompanhamento próprios. 
Os resultados obtidos não permitem sua generalização, porém, permitem concluir por uma adoção presente nas organizações da abordagem da contabilidade da gestão ambiental, em função das exigências de mercado, como as de investidores financeiros, e apontam ainda para um campo amplo de desenvolvimento em que técnicas como a do balanço de massa podem vir a ser incorporadas de maneira efetiva.

\section{Considerações finais}

Os levantamentos realizados indicam que a contabilidade da gestão ambiental tem seu papel reconhecido e apontado como elemento fundamental para o disclosure da questão ambiental nas empresas. Essa nova dimensão da contabilidade se dá, tanto em função de exigências externas (legais e de mercado) quanto internas, pela adoção de políticas explícitas do enfrentamento da questão ambiental no prisma da sustentabilidade.

Demonstrativos contábeis de empresas de ponta já se referem costumeiramente à questão ambiental, no seu enquadramento à dimensão mais ampla da responsabilidade social. Entretanto, o que se verificou nos casos analisados é uma diversidade de tratamento da gestão ambiental, nos relatórios destinados ao Brasil e ao exterior. Ou seja, as empresas estudadas que têm suas ações negociadas em bolsas no exterior detalham num grau relativamente maior seus demonstrativos e, mais que isso, têm as informações apresentadas auditadas por entidades externas, o que lhes confere um nível de credibilidade e de responsabilidade mais significativo.

Essa situação pode sugerir duas constatações: a simples obediência pragmática de ditames legais ou uma relativa importância dada à questão ambiental, que, apesar de presente nas comunicações empresariais de forma bastante elaborada, se vê contida pela política de transparência de informações públicas, inerente a qualquer tipo de organização.

Embora a metodologia adotada caracterize o estudo como exploratório, as indicações nesse sentido são evidentes. No entanto, cabe salientar que se apresenta um campo bastante vasto para a pesquisa acadêmica no campo da administração e da contabilidade, em particular, para o qual se vislumbra duas dimensões, a saber, a da investigação das formas, extensão e divulgação de tratamento contábil da gestão ambiental nas empresas e a exploração de novos procedimentos e indicadores que, com base ou a partir dos seus registros contábeis, contribuam para a tomada de decisão nas orga- 
nizações, contemplando a sustentabilidade como fundamental nas estratégias empresariais.

Assim, a contabilidade da gestão ambiental se apresenta como uma dimensão presente nas organizações, com seu uso indo ao encontro da missão fundamental da contabilidade e seu desenvolvimento atrelado, de forma inequívoca, às exigências da sociedade consciente à questão ambiental e, desejavelmente, de forma proativa ao avanço dos ditames legais.

\section{Referências bibliográficas}

ABAMEC (ASSOCIAÇÃO BRASILEIRA DE ANALISTAS DE MERCADO DE CAPITAIS). Seminário Meio Ambiente e os Resultados Financeiros, São Paulo, jun. 2002.

APIMEC (ASSOCIAÇÃO DOS PROFISSIONAIS ANALISTAS DE MERCADO DE CAPITAIS). Seminário Meio Ambiente e os Resultados Financeiros nos Setores Petróleo, Gás e Mineração. São Paulo, mar. 2004.

ATKINSON, A. A. et al. Contabilidade gerencial. São Paulo: Atlas, 2000.

BERGAMIN JR., S. Contabilidade e riscos ambientais. Revista do BNDES - Banco Nacional de Desenvolvimento Econômico e Social, Rio de Janeiro, n. 11, 1999.

DONAIRE, D. Gestão ambiental na empresa. 2. ed. São Paulo: Atlas, 1999.

EPA (ENVIRONMENTAL PROTECTION AGENCY). U.S. Environmental Protection Agency. Disponível em: <www.epa.gov>. Acesso em: 12 dez. 2002.

GRAY, R. A neutralidade da contabilidade? Disponível em: <www.gla.ac.uk/departments/ accounting/csear/studentresources/index.html>. Acesso em: 23 fev. 2003.

LIMA, D. V.; VIEGAS, W. Tratamento contábil e evidenciação das externalidades ecológicas. Revista Contabilidade \& Finanças, São Paulo: USP, n. 30, p. 46-53, set./dez. 2002.

MACEDO, R. K. Gestão Ambiental — os instrumentos básicos para a gestão ambiental de territórios e de unidades produtivas. Rio de Janeiro: Abes/Aidis, 1994.

ONU (ORGANIZAÇÃO DAS NAÇÕES UNIDAS). Contabilidad financiera y presentación de informes ambientales por las empresas. Disponível em: <www.unetad.org/sp/sphome. htm>. Acesso em: 15 nov. 2002.

Divisão para o Desenvolvimento Sustentável. Cooperação do Ministério Federal Austríaco dos Transportes, Inovação e Tecnologia. Assuntos Económicos \& Sociais. Contabilidade da gestão ambiental - procedimentos e princípios. 2001. Versão portuguesa de: PENEDA, C.; MARÇAL, M., colaboração SARAIVA, P.; SANTOS, C. Disponível em: <www.ioew.at/ioew/ download/EMA\%20_portuguese_complete.pdf>. Acesso em: 30 mar. 2003. 
RESPONSABILIDADE, sustentabilidade e contabilidade social e ambiental: o setor corporativo pode se pronunciar. Disponível em: <www.gla.ac.uk/departments/accounting/csear/ studentresources/index.html>. Acesso em: 25 nov. 2002.

TINOCO, J. E. P.; KRAEMER, M. E. P. Contabilidade e gestão ambiental. São Paulo: Atlas, 2004.

YIN, R. K. Case study research. Design and methods. EUA: Sage, 1990. 